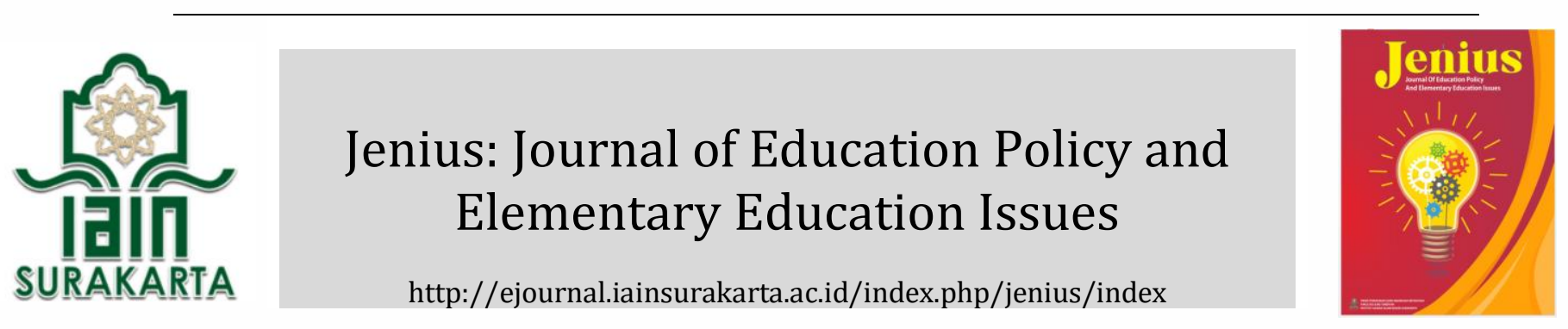

\section{Peningkatan Hasil Belajar Konsep Dasar IPA Melalui Model Pembelajaran Jigsaw}

\author{
Angga Dwi Prasetyo*
}

Pendidikan Guru Madrasah Ibtidaiyah, Fakultas Ilmu Tarbiyah, IAIN Surakarta, Indonesia

*Corresponding author: angga.dwiprasetyo@iain-surakarta.ac.id

\section{INFO ARTIKEL}

Riwayat Artikel
Diterima: 05-05-2021
Disetujui: 09-06-2021
Dipublikasikan: 19-07-
2021

\section{Kata kunci:}

Konsep Dasar IPA; Hasil

Belajar; Jigsaw

\section{Keywords:}

Basic Concepts of

Science; Jigsaw; Learning

Outcomes

\section{ABSTRAK}

Indonesia termasuk kedalam negara dengan peserta didik yang memiliki kemampuan literasi, sains serta matematika rendah berdasarkan skor Trends In International Mathematics and Science Study (TIMSS) dan Programme for International Student Assessment (PISA) tahun 2018, hal ini dapat dipengaruhi oleh banyak faktor seperti faktor internal maupun eksternal. Salah satu faktor eksternal yang mempengaruhi adalah pembelajaran yang terpusat pada pendidik dan metode penyampaian materi yang monoton, sehingga diperlukan suatu model pembelajaran yang interaktif, salah satunya model pembelajaran tipe jigsaw. Tujuan penelitian melihat pengaruh penerapan model jigsaw terhadap peningkatan hasil belajar peserta didik. Metode yang digunakan quassy experiment dengan pengambilan sampel secara purposive sampling dan analisis data menggunakan uji N-gain di kelas 4D dan 4C mahasiswa PGMI IAIN Surakarta. Hasil penelitian menunjukkan model jigsaw pada pembelajaran konsep dasar IPA dapat meningkatkan hasil belajar sebesar $0,72 \%$ yang termasuk kategori tinggi dibandingkan kelas kontrol. Selain itu penerapan model pembelajaran jigsaw juga dapat meningkatkan angka ketuntasan belajar pada peserta didik. Berdasarkan hasil penelitian, model pembelajaran jigsaw dapat meningkatkan hasil belajar peserta didik pada materi konsep dasar IPA.

\section{ABSTRACT}

Indonesia is included in a country with students who have low literacy, science and mathematics skills based on the Trends In International Mathematics and Science Study (TIMSS) and Program for International Student Assessment (PISA) scores in 2018, this can be influenced by many factors such as internal factors as well as external. One of the external factors that influence is educator-centered learning and monotonous methods of delivering material, so an interactive learning model is needed, one of which is the jigsaw type of learning model. The purpose of the study was to see the effect of the application of the jigsaw model on improving student learning outcomes. The method used is quassy experiment with purposive sampling and data analysis using the N-gain test in class $4 D$ and $4 C$ of PGMI IAIN Surakarta students. The results showed that the jigsaw model in learning basic science concepts could increase learning outcomes by $0.72 \%$ which was included in the high category compared to the control class. In addition, the application of the jigsaw learning model can also increase the number of students' learning mastery. Based on the results of the study, the jigsaw learning model can improve student learning outcomes on the basic concepts of science. 


\section{PENDAHULUAN}

Pendidikan memiliki makna berupa usaha sadar pendidik maupun instansi pendidikan untuk membuat suasana transfer ilmu dari pendidik kepada peserta didik menyenangkan. Hal ini dilakukan demi meningkatkan kualitas peserta didik agar terwujudnya tujuan pendidikan selaras Undang-Undang Pendidikan No. 20 tahun 2003 (Sujana, 2019). Demi terwujudnya tujuan pendidikan, tentunya peserta didik akan mendapatkan berbagai macam materi untuk meningkatkan pengetahuannya, salah satunya adalah konsep dasar IPA (Ilmu Pengetahuan Alam). Konsep dasar IPA memiliki arti penting tidak hanya mempelajari tentang benda dan makhluk hidup, namun menyangkut cara kerja, kemampuan berpikir kritis, serta cara memecahkan masalah (Sujana, 2014). Menurut Trowbridge \& Baybee dalam Sujana (2014) sciences as a way of knowing, yang berarti ilmu sains merupakan jalan atau proses untuk mengembangkan ataupun pengorganisasian pengetahuan, sementara dalam Permendiknas No. 22 Tahun 2006 tentang Standar Isi menyebutkan bahwa IPA merupakan ilmu pengetahuan yang berkaitan dengan ilmu yang mempelajari gejala alam secara sistematis, sehingga pembelajaran konsep dasar IPA tidak hanya untuk mengetahui fakta, konsep dan prinsip saja, tetapi juga merupakan proses penemuan (Yustiqvar et al., 2019). Sehingga pembelajaran konsep dasar IPA menjadi penting untuk dipelajari peserta didik untuk menumbuhkan kemampuan berpikir kritis pada peserta didik (Ramdani et al., 2020).

Hasil pengukuran Trends In International Mathematics and Science Study (TIMSS) atau kecenderungan pembelajaran sains dan matematika internasional pada tahun 2015 dengan dasar pengukuran menggunakan domain kognitif meliputi pengetahuan dibidang matematika dan sains, Indonesia berada di peringkat 46 dari 51 negara dengan skor 397, artinya kemampuan peserta didik Indonesia terhadap ilmu matematika dan sains masih sangat tertinggal dibandingkan peserta didik dari negara lain, hal ini menunjukkan masih kurangnya sistem maupun kurikulum yang berlaku di Indonesia, selain itu pada tahun 2018 Programme for International Student Assessment (PISA) menunjukkan kemampuan membaca, sains dan matematika, Indonesia tergolong rendah yaitu berada di peringkat 74 dari 79 negara (Dickey, 2018). Hal ini menunjukkan tingkat literasi di Indonesia khususnya pada pelajaran sains dan matematika tergolong rendah, sehingga diperlukan model pembelajaran baru dalam proses belajar yang dapat mempermudah peserta didik dalam memahami materi dan membuat suasana proses belajar dan mengajar menjadi menyenangkan, salah satunya model pembelajaran jigsaw.

Model pembelajaran jigsaw termasuk pembelajaran kooperatif dengan mengangkat 
kegiatan kerja sama atau gotong-royong antar peserta didik dengan membuat kelompokkelompok kecil dalam proses belajar dengan materi yang berbeda, selanjutnya antar kelompok akan bertukar informasi hasil diskusi kelompoknya sehingga menambah pengetahuan dan informasi. Pada model jigsaw terdapat proses tanya jawab antar kelompok dapat menumbuhkan kemampuan komunikasi dan interaksi antar peserta didik, pada model pembelajaran ini seorang pendidik dituntut untuk mengetahui karateristik setiap peserta didiknya, agar dapat membagi kelompok secara seimbang berdasarkan hasil pembelajaran sebelumnya, sehingga terjalinnya interaksi antar peserta didik yang dapat meningkatkan hasil belajar (Jarre \& Bachtiar, 2017).

Beberapa hasil penelitian yang dilakukan oleh Yetti (2018), Sulistijati (2019) dan Riyanto (2019) menggunakan aplikasi strategi dan berbagai metode dalam proses pembelajaran di kelas, secara umum menunjukkan terdapat peningkatan kemampuan berpikir dan peningkatan hasil belajar peserta didik menggunakan strategi dan model pembelajaran dibandingkan dengan metode konvensional. Berdasar latar belajang di atas, maka perlu dilakukannya penelitian terkait metode jigsaw pada materi konsep dasar IPA untuk melihat apakah terdapat peningkatan hasil belajar mahasiswa.

\section{METODE}

Metode yang digunakan dalam penelitian ini adalah Quasy Experiment sedangkan rancangan penelitian Pretest-Posttest Design (Sugiyono, 2014; 2015). Populasi pada penelitian adalah mahasiswa semester empat Pendidikan Guru Madrasah Ibtidaiyah IAIN Surakarta. Penelitian dilakukan pada bulan Oktober 2019. Terdapat dua sampel pada penelitian ini, yaitu kelas 4C (sebagai kontrol) dan kelas 4D (aplikasi model pembelajaran jigsaw). Pengambilan sampel secara purposive sampling. Pengukuran peningkatan hasil belajar peserta didik meliputi hasil belajar utama pada ranah kognitif, ranah afektif dan psikomotorik sebagai pendukung.

Pengukuran ranah kognitif menggunakan nilai pretest dan posttest, sedangkan ranah afektif dan psikomotorik diukur dengan observasi. Analisis kenaikan hasil belajar menggunakan uji N-gain. Analisis data ranah pendukung menggunakan secara deskriptif. Hasil belajar peserta didik dikatakan efektif apabila $\geq 80 \%$ mencapai kriteria ketuntasan minimal (KKM) sebesar 75, Terdapat kenaikan hasil belajar (N-Gain) pada kelas perlakuan $\geq 70 \%$ (Zumroh et al., 2018). Indikator keberhasilan dicapai apabila terdapat peningkatan hasil belajar pada sampel yang menggunakan aplikasi model Jigsaw pada konsep dasar IPA mengalami peningkatan rata-rata skor hasil belajar, peningkatan ketuntasan belajar dan terjadi perubahan sikap yang mengacu pada peningkatan aktivitas belajar. 


\section{HASIL DAN PEMBAHASAN}

Kelas perlakuan menggunakan model jigsaw diawali dengan pembagian kelompok oleh dosen terhadap peserta didik menjadi tiga kelompok dimana komposisi kelompok dibuat heterogen berdasarkan hasil ujian tengah semester, sehingga diharapkan dalam satu kelompok memiliki komposisi yang berbeda agar semua peserta didik menjadi aktif dalam berdiskusi atas materi yang diberikan, sedangkan pada kelas kontrol penyampaian materi secara konvensional menggunakan metode ceramah dan presentasi oleh dosen.

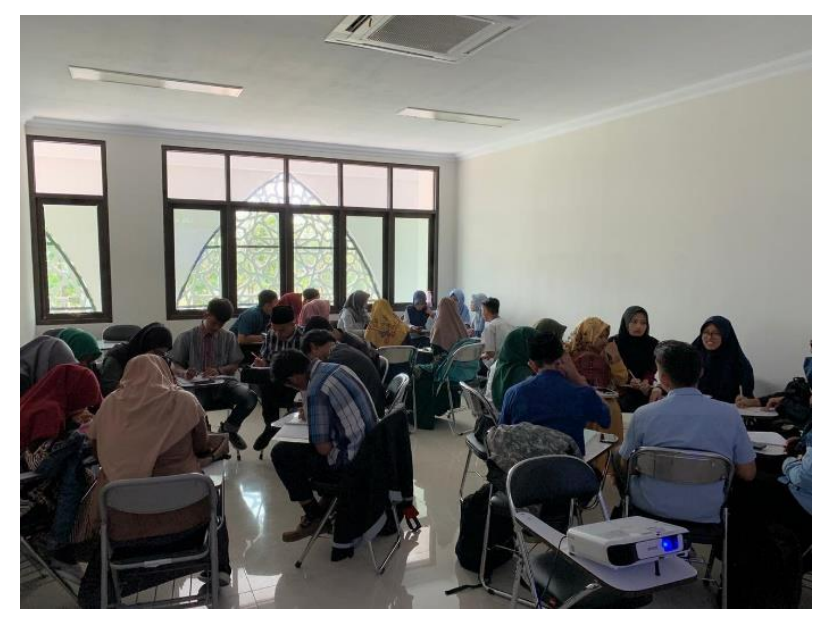

Gambar 1. Pembagian Kelompok pada Kelas Perlakuan Model Pembelajaran Jigsaw

Berdasarkan Gambar 1, peserta didik diberikan waktu diskusi selama 20 menit dengan pembahasan materi yang berbeda tiap kelompok, dan selanjutnya masing-masing kelompok akan berdiskusi dan memberikan pertanyaan maupun jawaban dari tiap kelompok jika ada penjelasan materi yang dianggap kurang lengkap oleh kelompok lain, sehingga masing-masing kelompok mendapatkan informasi dari semua kelompok yang terbentuk, tujuan model pembelajaran jigsaw adalah untuk meningkatkan kemampuan komunikasi, interaksi antar kelompok dan keaktifan selama proses belajar mengajar, sehingga suasana pbm menjadi menyenangkan, disisi lain calon guru harus memiliki kecakapan berupa ketelitian, kecermatan, komunikasi yang baik, serta manajemen waktu dan kemampuan berpikir kritis, sehingga dapat menjadi contoh yang baik dan mendorong eksplorasi diri peserta didik di berbagai macam bidang ilmu terutama IPA (Yuhanna \& Retno, 2016).

Data hasil pretest didapatkan sebelum memasuki materi pembelajaran dan post-test setelahnya hal ini dilakukan pada kelas kontrol dan aplikasi model pembelajaran jigsaw pada kelas perlakuan selanjutnya dilakukan analisis $\mathrm{N}$ gain untuk melihat perubahan pada peserta didik berupa peningkatan hasil belajar dan persentase distribusi dan jumlah ketuntasan belajar 
disajikan dalam bentuk tabel 1. Ketuntasan belajar dilihat berdasarkan daya serap masingmasing peserta didik terhadap materi konsep dasar IPA yang diberikan, penentuan tuntas ataupun tidak tuntas berdasarkan ketentuan ketuntasan minimum (KKM) yang telah ditetapkan.

Tabel 1. Distribusi, Jumlah Sampel dan Persentase Kategori Ketuntasan Belajar Materi Konsep Dasar IPA

\begin{tabular}{|c|c|c|c|c|c|c|c|c|c|}
\hline \multirow{3}{*}{ Kategori } & \multirow{3}{*}{ Nilai } & \multicolumn{4}{|c|}{ Kelas Kontrol } & \multicolumn{4}{|c|}{ Kelas Perlakuan } \\
\hline & & \multicolumn{2}{|c|}{ Pretest } & \multicolumn{2}{|c|}{ Post-test } & \multicolumn{2}{|c|}{ Pretest } & \multicolumn{2}{|c|}{ Post-test } \\
\hline & & $\sum \mathrm{S}$ & $\%$ & $\sum \mathrm{S}$ & $\%$ & $\sum \mathrm{S}$ & $\%$ & $\sum \mathrm{S}$ & $\%$ \\
\hline $\begin{array}{c}\text { Tidak } \\
\text { Tuntas }\end{array}$ & $0-64$ & 13 & 65 & 2 & 10 & 11 & 55 & 0 & 0 \\
\hline Tuntas & $65-100$ & 7 & 35 & 18 & 90 & 9 & 45 & 20 & 100 \\
\hline \multicolumn{2}{|c|}{ Jumlah } & 20 & 100 & 20 & 100 & 20 & 100 & 20 & 100 \\
\hline
\end{tabular}

Berdasarkan tabel 1, terlihat adanya peningkatan jumlah ketuntasan belajar materi konsep dasar IPA baik pada kelas control maupun kelas perlakuan, pada kelas kontrol persentase kenaikan jumlah siswa yang tuntas dari 35\% menjadi 90\% atau dari 7 peserta didik menjadi 18 peserta didik, sedangkan pada kelas perlakuan dengan model pembelajaran jigsaw persentase ketuntasan naik dari 45\% menjadi 100\%, dimana yang tadinya hanya 9 peserta didik menjadi 20 peserta didik setelah perlakuan. Hal ini menunjukkan siswa mudah memahami materi yang diberikan pada aplikasi model pembelajaran jigsaw, sehingga terdapat peningkatan hasil belajar peserta didik dilihat dari persentase kategori ketuntasan materi.

Berdasarkan tabel 1, terdapat dua peserta didik yang tidak tuntas, hal ini dapat disebabkan oleh banyak factor, menurut Zumroh et al., (2018) keberhasilan proses pembelajaran dapat dipengaruhi oleh faktor internal dan eksternal, dimana faktor yang ada dari dalam diri peserta didik yang meliputi kesehatan, minat, bakat, intelegensi dan motivasi dalam diri peserta didik yang masuk dalam kategori internal, sedangkan faktor eksternal merupakan pengaruh dari luar yang meliputi lingkungan kelas, sekolah dan keluarga (Rasidi \& Nuruddin, 2019). Sehingga dibutuhkan perlakuan yang ekstra dan khusus bagi peserta didik dengan cara penambahan jam belajar khusus peserta didik, pengayaan tambahan, upaya perbaikan nilai melalui remedial maupun penugasan sehingga tercapai ketuntasan belajar.

Selain itu pada saat proses pembelajaran menggunakan model jigsaw, dari waktu 25 menit yang diberikan untuk berdiskusi, rata-rata peserta didik membutuhkan waktu 10 menit untuk dapat aktif berdiskusi, hal ini dikarenakan beberapa faktor, seperti adanya siswa yang mendominasi diskusi dan siswa pasif, perlunya adaptasi peserta didik dengan kelompok 
diskusinya, kurang fokusnya peserta didik saat berdiskusi dan kurangnya kerjasama antar kelompok (Herawati et al., 2019), namun hal ini dapat terselesaikan pada pertengahan diskusi hingga akhir pembelajaran dengan cara memancing siswa untuk bertanya dan mengemukakan pendapat ketika diskusi sehingga meningkatkan kemampuan komunikasi peserta didik dan tingkat percaya diri peserta didik (Indriwati et al., 2018).

Keefektifan suatu model pembelajaran tidak hanya diukur dari hasil ketuntasan, peningkatan hasil belajar juga dapat menjadi tolak ukur pembelajaran yang efektif, pengukuran tingkatan hasil belajar menggunakan $\mathrm{N}$ gain, dimana nilai $\mathrm{N}$ gain dapat menjelaskan adanya peningkatan pada proses pembelajaran, yaitu pada pembelajaran konvensional maupun menggunakan model pembelajaran, tabel 2 menampilkan hasil analisis menggunakan $\mathrm{N}$ gain.

Tabel 2. Hasil Nilai N Gain Peserta Didik pada Materi Konsep Dasar IPA

\begin{tabular}{cccccc}
\hline \multirow{2}{*}{ Kelas } & \multirow{2}{*}{$\begin{array}{c}\text { Rata-rata N- } \\
\text { gain }\end{array}$} & Kriteria & \multicolumn{3}{c}{ Jumlah Siswa yang Mendapatkan N gain } \\
\cline { 4 - 6 } & & & Tinggi & Sedang & Rendah \\
\hline Kelas Kontrol & 0,50 & Sedang & $10 \%$ & $60 \%$ & $30 \%$ \\
\hline Kelas Perlakuan & 0,72 & Tinggi & $60 \%$ & $40 \%$ & $0 \%$ \\
\hline
\end{tabular}

Berdasarkan hasil tabel 2, menunjukkan N gain rata-rata kelas perlakuan menggunakan model pembelajaran jigsaw pada materi konsep dasar IPA sebesar 0,72 yang dimana termasuk kriteria tinggi, sedangkan kriteria sedang pada kelas kontrol sebesar 0,50, sehingga menunjukkan bahwa penggunaan jigsaw berpotensi meningkatkan hasil belajar pada peserta didik. Hal ini dapat terjadi karena pada jigsaw peserta didik berperan sebagai narasumber, sehingga peserta didik dituntut madiri, berpikir kritis dan merancang sendiri pengetahuan yang ada dalam pikirannya sehingga hal ini sejalan dengan teori kontruktivisme dimana teori Pendidikan yang megedepankan peningkatan perkembangan logika dan konseptual peserta didik, dengan berdiskusi dengan sesama peserta didik sehingga didapatkan rasa percaya diri, antusiasme dan interaksi tiap peserta didik sehingga membuat diskusi menjadi hidup dan suasana proses belajar menjadi menyenangkan, tujuan pembelajaran dapat tercapai dengan baik jika suasana kelas kondusif antara siswa dan guru (Santoso et al., 2018).

Pada distribusi jumlah siswa yang mendapatkan peningkatan hasil belajar, pada kelas kontrol hanya 10\% siswa yang mendapatkan peningkatan hasil belajar yang tinggi, sedangkan sebanyak 60\% mendapatkan peningkatan hasil belajar sedang dan sisanya 30\% rendah. Pembelajaran khususnya konsep dasar IPA yang memiliki banyak materi dan peyampaian dengan metode ceramah hanya beberapa siswa yang dapat fokus mendengarkan materi dari awal sampai akhir, selain itu pembelajaran yang berfokus ada pendidik membuat peserta didik 
menjadi pasif dan kurang rensponsif terhadap materi yang diberikan sehingga materi yang disampaikan tidak dapat diterima secara menyeluruh dan lengkap yang menyebabkan adanya peserta didik yang mendapatkan nilai rendah (Jarre \& Bachtiar, 2017).

Penerapan model pembelajaran jigsaw pada materi konsep IPA menunjukkan peningkatan hasil belajar yang signifikan dengan jumlah $60 \%$ peserta didik mendapatkan peningkatan hasil belajar yang tinggi dan sisanya $40 \%$ mendapatkan peningkatan hasil belajar yang sedang terhadap kelas kontrol, hasil ini dapat disebabkan karena pada model jigsaw peserta didik dituntut aktif berdiskusi antar anggotanya dan diakhir akan membagikan hasil diskusi kelompoknya dengan kelompok lain, sehingga proses transfer ilmu terjadi secara menyeluruh, peserta didik dengan komposisi yang heterogen dapat membantu peserta didik yang pasif untuk ikut aktif berdiskusi sehingga proses belajar menjadi menyenangkan. Selain itu jika pada proses belajar dengan metode konvensional siswa yang aktif hanya orang yang sama, dengan model jigsaw seluruh peserta didik menjadi aktif dan bekerjasama dalam berdiskusi tentang materi, yang menimbulkan rasa kebergantungan positif antar kelompok, menimbulkan rasa percaya diri siswa selaras dengan adanya kesempatan tanya jawab antar kelompok dan meningkatkan kemampuan interpersonal peserta didik maupun kemampuan kerjasama antar kelompok (Prasetyo \& Sasongko, 2014), sehingga menghasilkan kesamaan pemahaman konsep dari materi yang dibahas pada saat pembelajaran yang berdampak pada peningkatan hasil belajar yang tinggi dan menyeluruh pada seluruh siswa dikelas.

\section{KESIMPULAN DAN SARAN}

\section{Simpulan}

Penerapan model pembelajaran jigsaw pada materi konsep dasar IPA dapat memberikan suatu hal yang baru pada proses belajaran sehingga membuat suasana belajar menjadi menyenangkan dan meningkatkan pemahaman peserta didik akan materi yang ditunjukkan dengan hasil persentase ketuntasan belajar dan peningkatan hasil belajar peserta didik.

\section{Saran}

Penerapan model pembelajaran jigsaw dapat diaplikasikan pada materi pembelajaran yang berbeda, diperlukan jumlah sampel yang lebih banyak untuk validitas hasil dari penerapan model jigsaw dan perlu dilakukannya perbandingan degan model pembelajaran yang lain untuk melihat efektifiktas antar model pembelajaran. 


\section{DAFTAR RUJUKAN}

Dickey, E. M. (2018). Trends in international mathematics and science study (TIMSS). Encyclopedia of Educational Reform and Dissent, 562-569. doi: 10.4135/9781412957403.n438.

Herawati, L., \& Irwandi, I. (2019, October). Pengaruh model pembelajaran kooperatif tipe jigsaw terhadap hasil belajar dan berpikir kritis siswa pada mata pelajaran IPA di SMP Negeri 09 Lebong. In Seminar Nasional Sains \& Entrepreneurship (Vol. 1, No. 1). Retrieved from http://conference.upgris.ac.id/index.php/snse/article/view/211.

Indriwati, S. E., Susilo, H., \& Anggrella, D. P. (2018). Penerapan model pembelajaran inkuiri terbimbing berbasis lesson study pada matakuliah keanekaragaman hewan untuk meningkatkan kecakapan komunikasi dan hasil belajar kognitif mahasiswa pendidikan biologi. Jurnal Pendidikan Biologi, 9(2), 38-46.

Jarre, A. R., \& Bachtiar, S. (2017). Aktivitas dan hasil belajar kognitif siswa meningkat melalui penerapan model jigsaw. Jurnal Biologi \& Pembelajarannya, 4(1), 26-33.

Sulistijati, N. (2018). Peningkatan keaktifan dan hasil belajar siswa mata pelajaran sejarah materi perkembangan dunia pasca perang dunia ii melalui model pembelajaran aktif window shopping kelas XII. 8 semester 1 SMA Negeri 1 Bumiayu tahun pelajaran 2018/2019. DIALEKTIKA: Jurnal Pendidikan, 2(2), 63-74.

Prasetyo, A. D., \& Sasongko, H. (2014). Aktivitas antibakteri ekstrak etanol 96\% kulit buah manggis (garcinia mangostana l.) terhadap bakteri shigella dysenteriae dan bacillus subtilis sebagai materi pelajaran biologi SMA kelas X untuk mencapai kompetensi dasar 3.4 kurikulum 2013. Jupemasi-Pbio, 1(1), 98-102.

Ramdani, A., Jufri, A. W., Jamaluddin, J., \& Setiadi, D. (2020). Kemampuan berpikir kritis dan penguasaan konsep dasar IPA peserta didik. Jurnal Penelitian Pendidikan IPA, 6(1), 119124. doi: 10.29303/jppipa.v6i1.388.

Rasidi, M. A., \& Nuruddin. (2019). Pengaruh model pembelajaran kooperatif tipe windows shopping terhadap keterampilan berpikir kritis mahasiswa PGMI UIN MATARAM. Jurnal Elementary, 2(2), 31-33.

Riyanto, P. (2019). Pengaruh model pembelajaran jigsaw terhadap peningkatan kemampuan drible bola basket. Musamus Journal of Physical Education and Sport (MJPES), 2(01), 59-67. doi: 10.35724/mjpes.v2i01.2069.

Santoso, H., Riyanto, P., \& Haris, I. N. (2018). Pengaruh model pembelajaran tutor sebaya (peer taeching) terhadap motivasi belajar pendidikan jasmani siswa. Biormatika: Jurnal ilmiah fakultas keguruan dan ilmu pendidikan, 4(02), 68-80.

Sugiyono. (2014). Metode penelitian kuantitatif, kualitatif dan r\&d. Bandung: Alfabeta Rosdakarya. . (2015). Metode penelitian kuantitatif, kualitatif dan r\&d. Bandung: Alfabeta Rosdakarya.

Sujana, Atep. (2014). Dasar-dasar IPA: Konsep dan aplikasinya. Bandung: UPI PRESS. 
Sujana, I. W. C. (2019). Fungsi dan tujuan pendidikan Indonesia. Adi Widya: Jurnal Pendidikan Dasar, 4(1), 29-39.

Yetti, R. (2018). Model window shopping dalam pembelajaran membandingkan teks ulasan film pada siswa kelas XI tkr smk negeri 5 Pekanbaru. Journal on Education, 01(01), 75-82.

Yuhanna, W. L., \& Retno, R. S. (2016). The learning of science basic concept by using scientifiq inquiry to improve student's thinking, working, and scientific attitude abilities. Jurnal Pendidikan Biologi Indonesia, 2(1), 1-9. doi: 10.22219/jpbi.v2i1.2703.

Yustiqvar, M., Gunawan, G., \& Hadisaputra, S. (2019). Green chemistry based interactive multimedia on acid-base concept. Journal of Physics: Conference Series, 1364(1), 012006. doi: 10.1088/1742-6596/1364/1/012006.

Zumroh, N., Rahayu, E. S., \& Dewi, N. K. (2018). Keefektifan model pembelajaran window shopping dan pendekatan jelajah alam sekitar pada materi ekosistem. Journal of Biology Education, 7(2), 221-225. doi: 10.15294/jbe.v7i2.24269. 